\title{
Analytical modeling of plastic strain induced by deep rolling
}

\author{
kunpeng han ${ }^{1}$, Dinghua Zhang ${ }^{1}$, Changfeng Yao ${ }^{1}$, Liang Tan ${ }^{1}$, Zheng Zhou ${ }^{1}$, and Yu Zhao ${ }^{1}$ \\ ${ }^{1}$ Northwestern Polytechnical University
}

September 11, 2020

\begin{abstract}
To evaluate the through depth plastic strain generated by deep rolling, the analytical model of plastic strain was developed based on the Hertz contact theory. The analytical model of plastic strain was verified by numerical simulation. Then, the effect of rolling force, the diameter of the ball and ball material on the through depth plastic strain was investigated and validated by the through depth microhardness profiles. The results show that first method of the analytical model is more accurate, and the error of maximum plastic strain derived by the analytical model and finite element (FE) simulation is just $7.8 \%$. The through depth and relevant effective depth increase with the increase of rolling force; the through depth plastic strain decreases with increasing diameter of the ball. The tungsten carbide ball induces more plastic strain than the ball made of silicon nitride and steel. Moreover, the plastic strain profiles are in line with the variation of microhardness along with the depth.
\end{abstract}

\section{Hosted file}

Main document.docx available at https://authorea.com/users/355858/articles/480566-analyticalmodeling-of-plastic-strain-induced-by-deep-rolling

Hosted file

Figures.docx available at https://authorea.com/users/355858/articles/480566-analyticalmodeling-of-plastic-strain-induced-by-deep-rolling 